\title{
Rancang Bangun Aplikasi Penjualan Perlengkapan Olahraga (Studi Toko Baratha Sports)
}

\author{
Sinta Rukiastiandari- ${ }^{1}$, Yohanes Ulu Mado $^{2}$ \\ ${ }^{1}$ Universitas Bina Sarana Informatika \\ e-mail: sinta.sru@bsi.ac.id \\ ${ }^{2}$ Universitas Bina Sarana Informatika \\ e-mail: jo.adonara.23@gmail.com
}

Cara Sitasi: Rukiastiandari , S., \& Mado , Y. U. (2019). Rancang Bangun Aplikasi Penjualan Perlengkapan Olahraga (Studi Toko Baratha Sports). Jurnal Teknik Komputer, 43-50. doi:10.31294/jtk.v5i1.4287

\begin{abstract}
The Baratha Sports store is a store that serves various types of sales of sports equipment such as socks, soccer shoes, soccer clothes and other things. In 2013, this shop was founded by Mr. Tohir Adnan, located on Jalan Kinibalu Raya No.19 Harapan Jaya, Bekasi Utara. During this time the process of recording sales, processing the data of sporting goods and sales transaction data is still done using handwriting and still using book media. Difficulties in the process of recording sales and calculating the number of types and quantities of goods resulted in the data obtained being less accurate. To improve the accuracy of the data, it is necessary to develop a computerized sales information system.

In this writing the author will present a site on the internet that deals with the sale of sports equipment, which aims to convey information on the sale of sports equipment online, making it easier for consumers to purchase products from the Baratha Sports Shop. In this research phase the making of program code the author uses supporting software such as Xampp, Programming Language PHP, HTML, Jquery and CSS and databases using MySQL. and the method used using the Waterfall method. Mozilla Firefox as a browser, Microsoft paint for editing images.This application is expected to help users (users) in the transaction process ordering equipment and sports equipment, facilitate the checking of the amount of equipment available sports equipment and facilitate the company in disseminating information and product promotion.
\end{abstract}

Keywords: Design, application, sports equipment, sales, sports sales

\section{PENDAHULUAN}

Toko Baratha Sports merupakan sebuah toko yang melayani penjualan berbagai macam perlengkapan olahraga yang di dirikan oleh Bapak Tohir Adnan pada tahun 2013, dan berlokasi di Jalan Kinibalu Raya No.19 Harapan Jaya, Bekasi Utara. Dalam melakukan kegiatan penjualan, Toko Baratha Sports masih menggunakan media penyampaian informasi yang sederhana sehingga untuk pemasaran produk dan layanan masih belum maksimal. Pelanggan masih harus datang langsung ke toko untuk melihat produk yang diingikan. dengan demikian jangkauan pasarnya tebatas hanya dapat memasarkan produk di sekitar toko saja. dan pemilik toko pun masih harus melayani pelanggan secara langsung dan mencatat data penjualan, membuat laporan pembelian dan data stok barang secara manual sehingga kegiatan penjualan perlengkapan olahraga menjadi kurang efisien.
Dengan masalah yang dihadapi oleh Toko Baratha Sports, maka dibutuhkan sebuah sistem informasi berbasis web. Atas dasar identifikasi masalah yang telah dipaparkan, maka rumusan masalah pada tugas akhir ini adalah bagaimana membangun aplikasi e-commerce pada Toko Baratha Sports untuk membantu pemilik toko dalam memasarkan produk tanpa biaya lebih dan memudahkan dalam kegiatan pengolahan data menjadi lebih terstruktur serta membantu pelanggan dalam mengakses informasi yang dibutuhkan kapan saja dan dimana saja. Produk yang di jual pada Toko Baratha Sports adalah jersey bola, sepatu futsal, sepatu sepak bola, kaos kaki bola, bola basket, bola sepak, bola pingpong, raket bulutsngkis, bola kok, bola voli dan lain-lain.

Berikut ini adalah laporan pergerakan pembelian perlengkapan olahraga tahun 2017 yang dimulai dari bulan Januari sampai bulan Maret 2017 adalah sebagai berikut : 


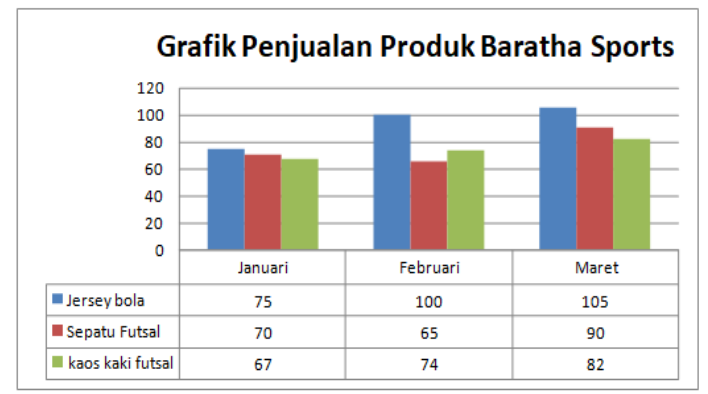

Sumber : Toko Baratha Sports

\section{Gambar 1.Grafik penjualan dari bulan Januari s.d Maret 2017}

Dari keterangan gambar diagram diatas menjelaskan tentang perbadingan penjualan yang dilakukan selama 3 (tiga) bulan dengan membandingkan jenis barang penjualan perlengkapan olah raga. Adapun jenis barang yang paling banyak terjual adalah Jersey bola yaitu sebanyak 280 pcs, Sepatu futsal sebanyak 225 pcs dan Kaos kaki futsal sebanyak 223 pcs.

\section{Pengertian Website}

Menurut (Ardhan, 2012) "World Wide Web atau lebih sering dikenal sebagai web adalah suatu layanan sajian informasi yang menggunakan konsep hyperlink (tautan), yang memudahkan surfer (sebutan para pemakai komputer yang melakukan browsing atau penelusuran informasi melalui internet). Keistimewaan inilah yang telah menjadikan web sebagai service yang paling cepat pertumbuhannya."

\section{Pengertian Internet}

Menurut (Anhar, 2016)“internet adalah jaringan atau sistem pada jaringan komputer yang saling berhubungan (terhubung) dengan menggunakan Sistem Global Transmission Control Protocol atau Internet Protocol Suite (TCP/IP) sebagai protocol pertukaran paket (packet switching communication protocol) untuk melayani milyaran pengguna di seluruh dunia"

3. Pengertian Web Server

Menurut (Pratama, 2015) "Web server merupakan perangkat lunak yang dijalankan di sistem operasi pada komputer server maupun dekstop, yang berfungsi untuk menerima permintaan (request) dalam bentuk protocol, misalkan HTTP (Hyper Text Tranfer Protocol) dan HTTPS (Hyper Text Transfer Protocol Secure)".

4. Model SDLC Air Terjun (Waterfall)

Menurut (Sukamto, 2014) "Model air terjun menyediakan pendekatan alur hidup perangkat lunak secara sekuensial atau terurut dimulai dari analisis, desain, pengkodean, pengujian, dan tahap pendukung (Support)". Dapat dilihat pada gambar II dibawah ini.

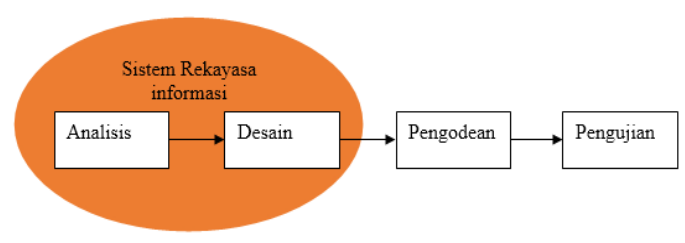

Sumber : Sukamto dan Shalahuddin (2014) Gambar 2. Ilustrasi Model Waterfall

\section{METODOLOGI PENELITIAN}

Pengumpulan data yang diterapkan oleh peneltian ini adalah sebagai berikut:

1. Metode Pengamatan Langsung (Observasi)

Dalam hal ini penulis melakukan riset secara langsung sehingga diperoleh gambaran dan pedoman mengenai pemasaran yang dilakukan oleh Toko Baratha Sports.

2. Metode Wawancara (Interview)

Dalam penulisan tugas akhir ini, untuk mendapatkan informasi secara lengkap maka penulis melakukan suatu metode tanya jawab kepada Bapak Tohir Adnan selaku pemilik toko khusus mengenai semua kegiatan dalam sistem yang berhubungan dengan penjualan perlengkapan olahraga pada Toko Baratha Sports.

3. Metode Studi Pustaka (Library Research)

Selain melakukan kegiatan diatas penulis juga melakukan studi kepustakaan melalui literaturliteratur atau referensi-referensi yang ada diperpustakaan Universitas Bina Sarana Informatika maupun diperpustakaan lainnya.

Berikut tahapan metode waterfall yang digunakan pada penelitian ini, antara lain :

1. Analisa

Analisa adalah penjabaran dari suatu sistem informasi yang utuh kedalam berbagai bagian dengan komponennya. Dengan maksud agar bisa mengidentifikasi dan mengevaluasi berbagai macam masalah yang timbul pada sistem sehingga nantinya bisa dilakukan penanggulangan perbaikan dan juga pengembagan.

2. Perancangan

Perancangan sistem dapat didefinisikan sebagai penggambaran, perencanaan, dan pengaturan dari beberapa elemen terpisah ke dalam satu kesatuan yang utuh dan berfungsi. Tujuan dari rancangan sistem adalah untuk memenuhi kebutuhan kepada pemakai sistem, dan untuk memberikan gambaran secara jelas dan rancang bangun yang lengkap kepada pemrogram komputer dan ahli-ahli teknik lainnya.

3. Desain

Membuat program dan desain pemograman yang diperlukan untuk pengembangan sistem informasi serta memberikan gambaran yang jelas bagaimana suatu sistem yang dibentuk.

4. Implementasi 
Suatu proses penerapan sistem penjualan berbasis web pada toko agar dapat berfungsi sebagaimana yang diharapkan dan untuk mengetahui sejauh mana informasi yang disajikan, maka dilakukan pengetesan serta uji coba guna menghindari adanya kesalahan yang mungkin terjadi, sehingga pengembangan dan perbaikkan.

\section{HASIL DAN PEMBAHASAN}

\section{Analisa Sistem Berjalan}

Analisis kebutuhan informasi ini dilakukan dengan melihat proses penjualan perlengkapan olahraga yang berada di Baratha Sports dan melihat informasi apa saja yang dibutuhkan oleh pembeli. Hasil dari analisis ini menyimpulkan bahwa saat ini proses penjualan masih dilakukan secara manual dimana penjual dan pembeli bertatap muka secara langsung serta proses pencatatan laporan penjualan masih dilakukan dengan menggunakan tulisan tangan dengan menggunakan media buku.

\section{Perancangan Sistem}

\subsection{Pembuatan Alur Kerja Sistem}

Sistem pembuatan alur kerja sistem ini adalah dengan cara menentukan tabel-tabel dari database yang dibutuhkan. Table-tabel yang digunakan adalah sebagai berikut :

1. Tabel Pelanggan, yang berisi kd_pelanggan, nm_pelanggan, kelamin, email, no_telepon, username, password, dan tgl_daftar. Tabel ini digunakan untuk menyimpan data pelanggan

Tabel 1. Pelanggan

\begin{tabular}{cccccc}
\hline $\mathrm{N}$ & Elemen & Nama & Tipe & Panja & Ket \\
$\mathrm{o}$ & Data & Field & Data & ng & \\
\hline 1 & Kode & kd_pela & Char & 6 & Prim \\
& Pelangg & nggan & & & ary \\
& an & & & & Key,
\end{tabular}

\begin{tabular}{|c|c|c|c|c|}
\hline 2 & $\begin{array}{c}\text { Nama } \\
\text { Pelangg } \\
\text { an }\end{array}$ & $\begin{array}{c}\text { nm_pela } \\
\text { nggan }\end{array}$ & $\begin{array}{c}\text { Varch } \\
\text { ar }\end{array}$ & 100 \\
\hline 3 & $\begin{array}{c}\text { Jenis } \\
\text { Kelamin }\end{array}$ & Kelamin & Enum & - \\
\hline 4 & Email & Email & $\begin{array}{c}\text { Varch } \\
\text { ar }\end{array}$ & 100 \\
\hline 5 & $\begin{array}{l}\text { Nomor } \\
\text { Telepon }\end{array}$ & $\begin{array}{c}\text { no_telep } \\
\text { on }\end{array}$ & $\begin{array}{c}\text { Varch } \\
\text { ar }\end{array}$ & 20 \\
\hline 6 & $\begin{array}{l}\text { Userna } \\
\text { me }\end{array}$ & $\begin{array}{l}\text { Userna } \\
\text { me }\end{array}$ & $\begin{array}{c}\text { Varch } \\
\text { ar }\end{array}$ & 20 \\
\hline 7 & $\begin{array}{c}\text { Passwor } \\
\text { d }\end{array}$ & $\begin{array}{c}\text { Passwor } \\
\mathrm{d}\end{array}$ & $\begin{array}{c}\text { Varch } \\
\text { ar }\end{array}$ & 100 \\
\hline 8 & Tanggal & tgl_daft & Date & - \\
\hline
\end{tabular}
Daftar
ar

Sumber : Hasil Penelitain (2017)

2. Tabel Konfirmasi, yang berisi id, no_pemesanan, nm_pelanggan, jumlah_transfer, keterangan, dan tanggal. Tabel ini digunakan untuk menyimpan data konfirmasi.

Tabel 2. Konfirmsi

\begin{tabular}{cccccc}
\hline $\begin{array}{c}\mathrm{N} \\
\mathrm{o}\end{array}$ & $\begin{array}{c}\text { Elemen } \\
\text { Data }\end{array}$ & $\begin{array}{c}\text { Nama } \\
\text { Field }\end{array}$ & $\begin{array}{c}\text { Tipe } \\
\text { Data }\end{array}$ & $\begin{array}{c}\text { Panja } \\
\text { ng }\end{array}$ & Ket \\
\hline 1 & Id & Id & Intege & 4 & Prim \\
& & & $r$ & & ary \\
& & & & & Key, \\
& & & & & Auto \\
& & & & & Incre \\
& & & & & ment
\end{tabular}

$2 \begin{array}{cccc}\text { Nomor } & \text { no_pe } & \text { Varch } & 8\end{array}$
an an

\begin{tabular}{ccccc}
\hline 3 & $\begin{array}{c}\text { Nama } \\
\text { Pelangga } \\
\mathrm{n}\end{array}$ & $\begin{array}{c}\text { nm_pe } \\
\text { langga } \\
\mathrm{n}\end{array}$ & $\begin{array}{c}\text { Varch } \\
\text { ar }\end{array}$ & 100 \\
& & & \\
\hline 4 & $\begin{array}{c}\text { Jumlah } \\
\text { Transfer }\end{array}$ & $\begin{array}{c}\text { jumla } \\
\text { h_tran } \\
\text { sfer }\end{array}$ & $\begin{array}{c}\text { Intege } \\
r\end{array}$ & 12 \\
& & & \\
\hline 5 & $\begin{array}{c}\text { Keterang } \\
\text { an }\end{array}$ & $\begin{array}{c}\text { Ketera } \\
\text { ngan }\end{array}$ & Text & \\
& & Tangg & Date & \\
\hline 6 & Tanggal & al & & \\
& & &
\end{tabular}

Sumber : Hasil Penelitain (2017)

\subsection{Pembuatan Model UML}

\section{Use Case Diagram}

Use case diagram digunakan untuk menunjukkan peran aktor (user) kedalam sistem. Gambar 3 menunjukkan use case diagram pada perancangan aplikasi untuk melihat menu lukisan. User dapat melihat dan memilih produk tanpa harus login terlebih dahulu ke sistem dan jika user ingin melakukan pemesanan produk maka user harus mengisi dan melengkapi data pemesanan. Admin harus melewati proses login terlebih dahulu dengan mengisi username dan password untuk merubah dan menambahkan isi data barang. 


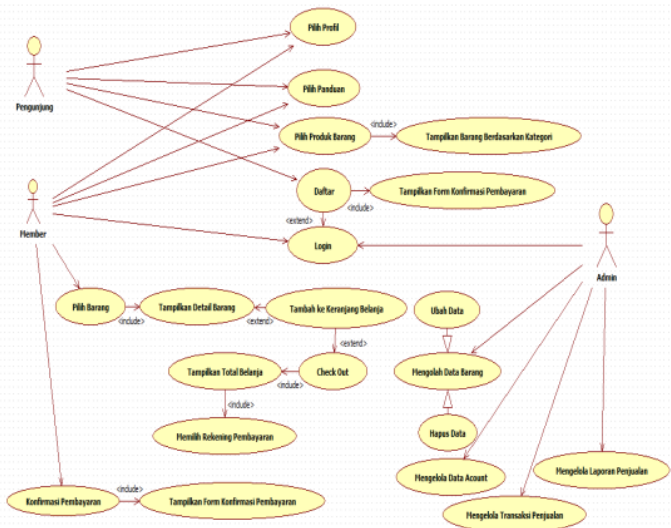

Gambar 3. Use Case Diagram Aplikasi Penjualan Perlengkapan Olahraga

\section{Class Diagram}

Class diagram digunakan untuk menampilkan kelas - kelas di dalam sistem dan hubungan relasi yang memberikan gambaran sistem secara statis. Pada Aplikasi Penjualan Perlengkapan Olahraga ini nama kelas yang ada didalam sistem terdiri dari Kelas Barang, Kelas Kategori Kelas Produk dan Kelas Pemesanan, Kelas Konfirmasi, Kelas Pelanggan, Kelas Detail Pemesanan dan Kelas Provinsi.

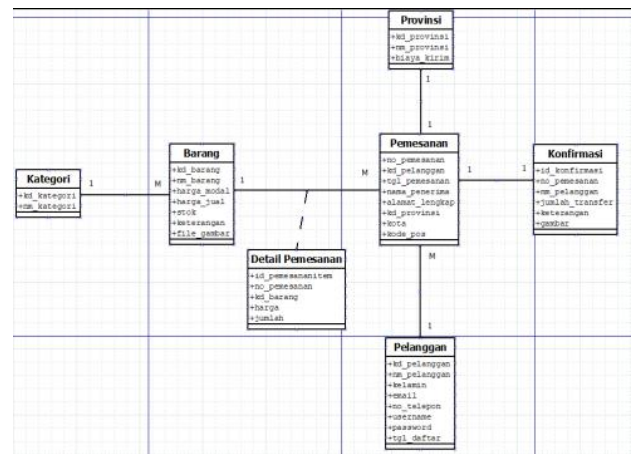

Sumber : Hasil Penelitian (2017)

Gambar 4. Class Diagram Aplikasi

Penjualan Perlengkapan Olahraga

\section{Sequence Diagram}

Penggambarannya dibagi berdasarkan aktivitas-aktivitas yang dilakukan oleh aktor yang terlibat. Berikut ini adalah aktivitas yang dilakukan oleh aktor yaitu

1. Menu Login

Menu login ini dilakukan oleh seorang Admin dimana admin tersebut diharuskan membuka menu login terlebih dahulu dan diwajibkan mengisi Username dan Password kemudian password tersebut akan disimpan ke dalam suatu data base.

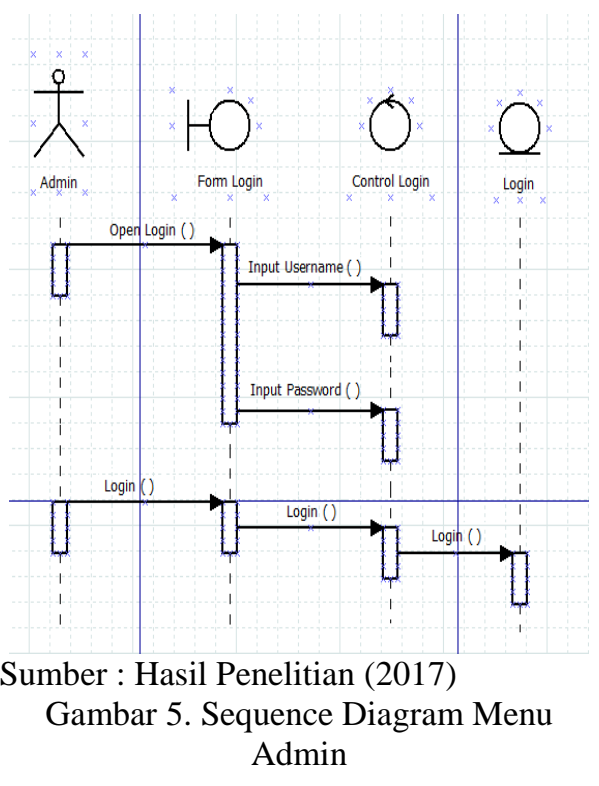

2. Menu Pendaftaran Pelanggan

Menu Pendaftaran Pelanggan dilakukan oleh seorang Pembeli, untuk pengisian data ini pembeli terlebih dahulu harus mendaftarkan diri untuk menjadi member pelanggan, dengan mengisi nama, email, no telepon, user name dan password. Berikut tampilannya seperti pada gambar 6

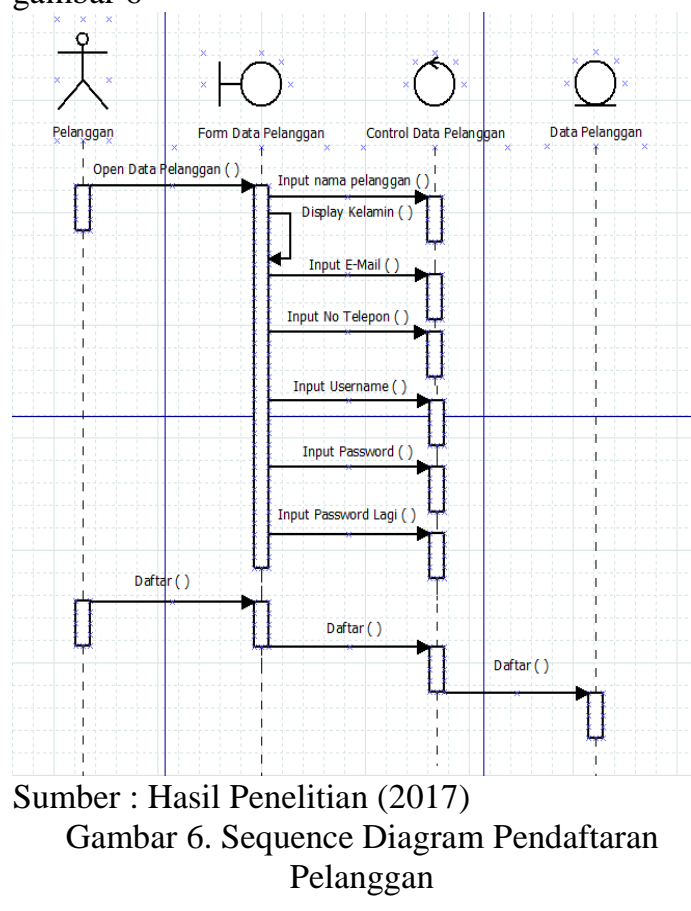

3. Menu Konfirmasi Pembayaran

Tampilan ini digunakan untuk konfirmasi pembayaran setelah member pelanggan melakukan pembayaran dengan cara ditransfer ke rekening pemilik toko atas pembelian barang yang dipesan. Berikut bentuk tampilannya seperti pada gambar 7 . 


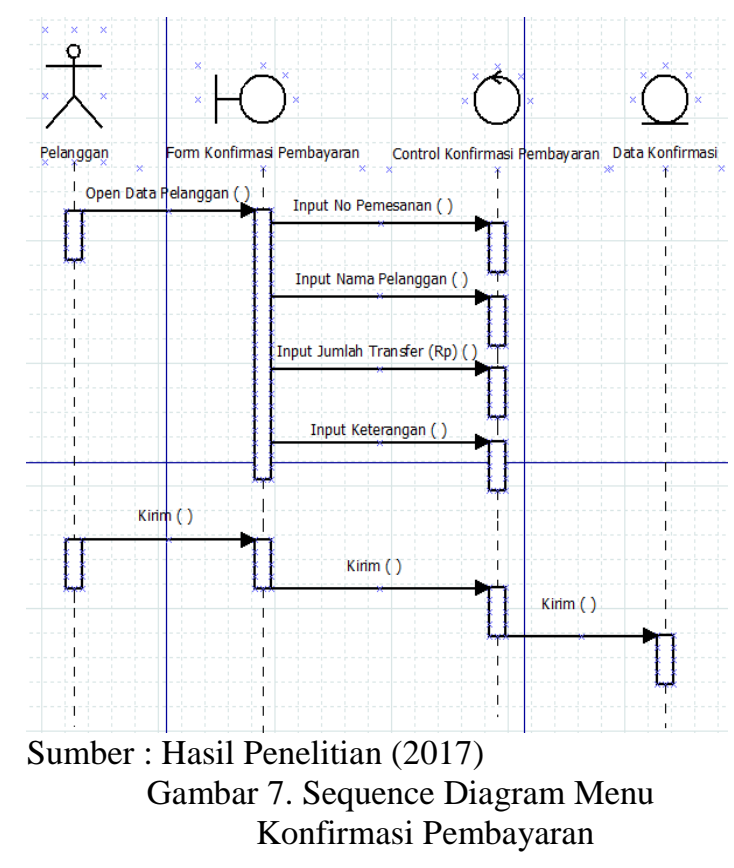

\section{Implementasi}

Tahap ini adalah tahap persiapan pembuatan rancangan aplikasi antar muka yang terdiri dari :

1. Halaman Login Admin

Admin harus melakukan login terlenih dahulu untuk dapat menggunakan modul-modul yang tersedia jika login berhasil maka menu-menu yang sesuai dengan akses admin akan ditampilkan seperti gambar 8 .

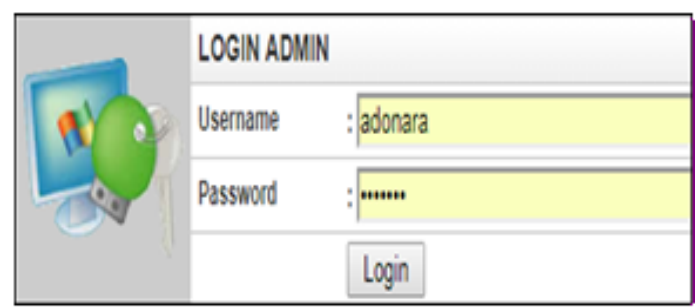

Sumber : Data Program (2017)

Gambar 8. Halaman Login Admin

2. Halaman Daftar Pelanggan

Untuk dapat memesan barang pada website ini, calon pembeli yang belum terdaftar harus mendaftar terlebih dahulu melalui halaman daftar. Data pembeli yang tersimpan digunakan sebagai data untuk login dan sebagai inforamasi acuan bagi administrator tentang pemesanan barang yang dilakukan pembeli.

\begin{tabular}{|c|c|c|}
\hline \multicolumn{3}{|c|}{ PENDAFTARAN PELANGGAN } \\
\hline $\begin{array}{l}\text { Nama } \\
\text { Pelanggan }\end{array}$ & $:$ & \\
\hline Kelamin & : Laki-laki $\quad$ & \\
\hline E-Mail & : & \\
\hline No. Telepon & $:$ & \\
\hline \multicolumn{3}{|l|}{ DATA LOGIN } \\
\hline Username & $:$ & \\
\hline Password & : & \\
\hline \multirow[t]{2}{*}{ Password (Lagi) } & : & \\
\hline & Daftar & \\
\hline
\end{tabular}

Sumber : Data Program (2017)

\section{Gambar. 9. Halaman Daftar Pelanggan}

3. Halaman Konfirmasi Pembayaran

Halaman ini menampilkan form isian data konfirmasi pembayaran untuk memberitahukan bahwa telah melakukan proses transaksi pembayaran barang melalui transfer rekening bank, halaman ini di tunjukan pada gambar 10

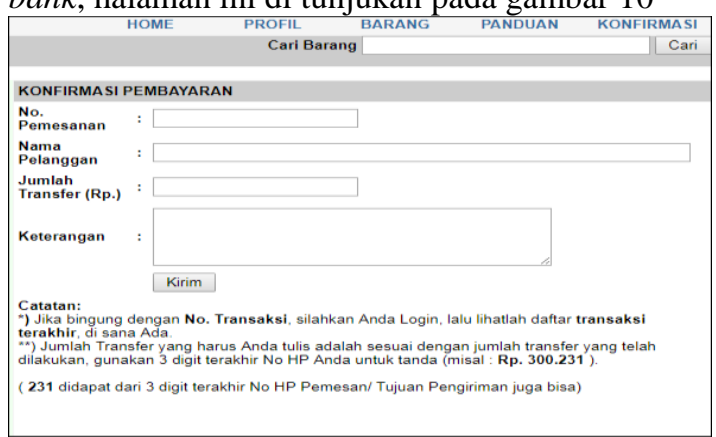

Sumber : Data Program (2017)

Gambar 10. Halaman Konfirmasi Pembayaran

2. Pengujian Terhadap Unit

a. Pengujian Terhadap Pendaftaran Pelanggan

Tabel 2.

Pengujian Black Box Testing Halaman Pendaftaran Pelanggan

\begin{tabular}{llllll}
\hline N Skenar & Test & Hasil & Hasil & Kesi \\
o io & Case & yang & Penguj & mpul \\
. Penguj & & diharapka & ian & an \\
& ian & & $n$ & &
\end{tabular}




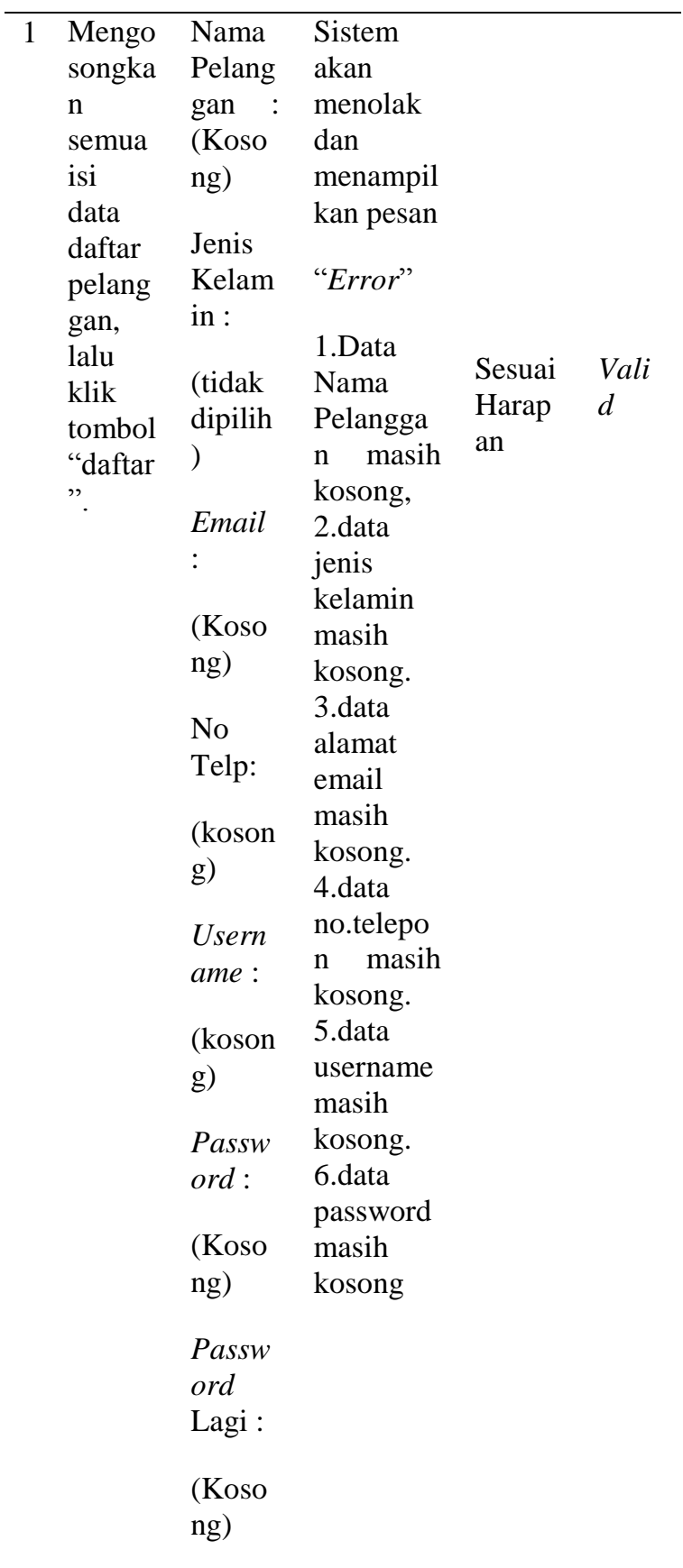

\begin{tabular}{|c|c|c|c|c|}
\hline $\begin{array}{l}\text { Hanya } \\
\text { mengis } \\
\text { i data } \\
\text { nama } \\
\text { Pelang } \\
\text { gan } \\
\text { dan } \\
\text { mengo } \\
\text { songka } \\
\text { n data } \\
\text { lain, } \\
\text { lalu } \\
\text { klik } \\
\text { tombol } \\
\text { "daftar } \\
\text { ”. }\end{array}$ & $\begin{array}{l}\begin{array}{l}\text { Nama } \\
\text { Pelang } \\
\text { gan } \\
\text { john }\end{array} \\
\text { Jenis } \\
\text { Kelam } \\
\text { in : } \\
\text { (tidak } \\
\text { dipilih } \\
\text { ) } \\
\text { Email } \\
\text { : } \\
\text { (Koso } \\
\text { ng) } \\
\text { No } \\
\text { Telp: } \\
\text { (koson } \\
\text { g) } \\
\text { Usern } \\
\text { ame : } \\
\text { (koson } \\
\text { g) } \\
\text { Passw } \\
\text { ord: } \\
\text { (Koso } \\
\text { ng) } \\
\text { Passw }\end{array}$ & $\begin{array}{l}\text { Sistem } \\
\text { akan } \\
\text { menolak } \\
\text { dan } \\
\text { menampil } \\
\text { kan pesan } \\
\text { 1.data } \\
\text { jenis } \\
\text { kelamin } \\
\text { belum } \\
\text { dipilih. } \\
\text { 2.data } \\
\text { alamat } \\
\text { email } \\
\text { masih } \\
\text { kosong. } \\
\text { 3.data } \\
\text { no.telepo } \\
\text { n masih } \\
\text { kosong. } \\
\text { 4.data } \\
\text { username } \\
\text { masih } \\
\text { kosong. } \\
\text { 5.data } \\
\text { password } \\
\text { masih } \\
\text { kosong }\end{array}$ & $\begin{array}{l}\text { Sesuai } \\
\text { Harap } \\
\text { an }\end{array}$ & $\begin{array}{l}\text { Vali } \\
d\end{array}$ \\
\hline
\end{tabular}

(Koso

ng)

\begin{tabular}{lllll}
\hline Hanya & Nama & Sistem & & \\
mengis & Pelang & akan & & \\
i data & gan : & menolak & Sesuai & Vali \\
nama & john & dan & Harap & $d$ \\
Pelang & & menampil an & \\
gan & Jenis & kan pesan & \\
dan & Kelam & & \\
jenis & in : & "Error" & \\
kelami & & & \\
n dan & Laki- & 1.data \\
mengo & Laki & alamat \\
songka & Email & email \\
n data & masih & \\
lain, & : & kosong. \\
lalu & & 2.data & \\
klik & (Koso & no.telepo & \\
tombol & ng) & n masih & \\
"daftar & No & kosong. & \\
\hline
\end{tabular}




\begin{tabular}{|c|c|c|c|c|c|c|c|c|c|c|c|}
\hline \multirow[t]{2}{*}{ 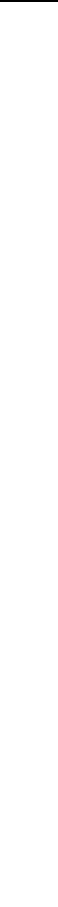 } & \multirow[t]{2}{*}{$"$} & $\begin{array}{l}\text { Telp: } \\
\text { (koson } \\
\text { g) }\end{array}$ & \multirow{2}{*}{$\begin{array}{l}\text { 3.data } \\
\text { username } \\
\text { masih } \\
\text { kosong. } \\
\text { 4.data } \\
\text { password } \\
\text { masih } \\
\text { kosong }\end{array}$} & & & & & $\begin{array}{l}\text { Lagi : } \\
\text { (Koso } \\
\text { ng) }\end{array}$ & & \multirow[b]{2}{*}{$\begin{array}{l}\text { Sesuai } \\
\text { Harap } \\
\text { an }\end{array}$} & \multirow[b]{2}{*}{$\begin{array}{l}\text { Vali } \\
d\end{array}$} \\
\hline & & $\begin{array}{l}\begin{array}{l}\text { Usern } \\
\text { ame: }\end{array} \\
\text { (koson } \\
\mathrm{g}) \\
\text { Passw } \\
\text { ord: } \\
\text { (Koso } \\
\text { ng) } \\
\text { Passw } \\
\text { ord } \\
\text { Lagi : } \\
\text { (Koso } \\
\text { ng) }\end{array}$ & & & & 5 & $\begin{array}{l}\text { Hanya } \\
\text { mengis } \\
\text { i data } \\
\text { nama } \\
\text { Pelang } \\
\text { gan } \\
\text { dan } \\
\text { jenis } \\
\text { kelami } \\
\text { n, } \\
\text { Email, } \\
\text { no } \\
\text { telepo } \\
\text { n dan } \\
\text { mengo } \\
\text { songka } \\
\text { n data } \\
\text { lain, }\end{array}$ & $\begin{array}{l}\begin{array}{l}\text { Nama } \\
\text { Pelang } \\
\text { gan : } \\
\text { john }\end{array} \\
\text { Jenis } \\
\text { Kelam } \\
\text { in : } \\
\text { Laki- } \\
\text { Laki } \\
\text { Email } \\
\text { : } \\
\text { john@ } \\
\text { gmail. } \\
\text { com }\end{array}$ & $\begin{array}{l}\text { Sistem } \\
\text { akan } \\
\text { menolak } \\
\text { dan } \\
\text { menampil } \\
\text { kan pesan } \\
\text { "Error" } \\
\text { 1.data } \\
\text { password } \\
\text { masih } \\
\text { kosong }\end{array}$ & & \\
\hline 4 & $\begin{array}{l}\text { Hanya } \\
\text { mengis } \\
\text { i data } \\
\text { nama } \\
\text { Pelang } \\
\text { gan } \\
\text { dan } \\
\text { jenis } \\
\text { kelami } \\
\text { n, } \\
\text { Email } \\
\text { dan } \\
\text { mengo } \\
\text { songka } \\
\text { n data } \\
\text { lain, } \\
\text { lalu } \\
\text { klik } \\
\text { tombol } \\
\text { “daftar } \\
\text { ”. }\end{array}$ & $\begin{array}{l}\begin{array}{l}\text { Nama } \\
\text { Pelang } \\
\text { gan : } \\
\text { john }\end{array} \\
\text { Jenis } \\
\text { Kelam } \\
\text { in : } \\
\text { Laki- } \\
\text { Laki } \\
\text { Email } \\
: \\
\text { john@ } \\
\text { gmail. } \\
\text { com } \\
\text { No } \\
\text { Telp: } \\
\text { (koson } \\
\text { g) }\end{array}$ & $\begin{array}{l}\text { Sistem } \\
\text { akan } \\
\text { menolak } \\
\text { dan } \\
\text { menampil } \\
\text { kan pesan } \\
\text { 1.data } \\
\text { no.telepo } \\
\text { n masih } \\
\text { kosong. } \\
\text { 2.data } \\
\text { username } \\
\text { masih } \\
\text { kosong. } \\
\text { 3.data } \\
\text { password } \\
\text { masih } \\
\text { kosong }\end{array}$ & $\begin{array}{l}\text { Sesuai } \\
\text { Harap } \\
\text { an }\end{array}$ & $\begin{array}{l}\text { Vali } \\
d\end{array}$ & & $\begin{array}{l}\text { lalu } \\
\text { klik } \\
\text { tombol } \\
\text { "daftar } \\
\text { ". }\end{array}$ & $\begin{array}{l}\text { No } \\
\text { Telp: } \\
08229 \\
84188 \\
\text { Usern } \\
\text { ame: } \\
\text { (koson } \\
\text { g) } \\
\text { Passw } \\
\text { ord: } \\
\text { (Koso } \\
\text { ng) } \\
\text { Passw } \\
\text { ord } \\
\text { Lagi : } \\
\text { (Koso } \\
\text { ng) }\end{array}$ & & & \\
\hline & & $\begin{array}{l}\text { Usern } \\
\text { ame: } \\
\text { (koson } \\
\mathrm{g}) \\
\text { Passw } \\
\text { ord: } \\
\text { (Koso } \\
\text { ng) } \\
\text { Passw } \\
\text { ord }\end{array}$ & & & & 6 & $\begin{array}{l}\text { Hanya } \\
\text { mengis } \\
\mathrm{i} \text { data } \\
\text { nama } \\
\text { Pelang } \\
\text { gan } \\
\text { dan } \\
\text { jenis } \\
\text { kelami } \\
\text { n, } \\
\text { Email, } \\
\text { no } \\
\text { telepo }\end{array}$ & $\begin{array}{l}\begin{array}{l}\text { Nama } \\
\text { Pelang } \\
\text { gan : } \\
\text { john }\end{array} \\
\text { Jenis } \\
\text { Kelam } \\
\text { in : } \\
\text { Laki- } \\
\text { Laki } \\
\text { Email }\end{array}$ & $\begin{array}{l}\text { Sistem } \\
\text { akan } \\
\text { menolak } \\
\text { dan } \\
\text { menampil } \\
\text { kan pesan } \\
\text { "Data } \\
\text { password } \\
\text { harus } \\
\text { diisi". }\end{array}$ & $\begin{array}{l}\text { Sesuai } \\
\text { Harap } \\
\text { an }\end{array}$ & $\begin{array}{l}\text { Vali } \\
d\end{array}$ \\
\hline
\end{tabular}




\begin{tabular}{|c|c|c|c|c|c|}
\hline & $\begin{array}{l}\mathrm{n}, \\
\text { Usern } \\
\text { ame } \\
\text { dan } \\
\text { mengo } \\
\text { songka } \\
\mathrm{n} \text { data } \\
\text { lain, } \\
\text { lalu } \\
\text { klik } \\
\text { tombol } \\
\text { "daftar } \\
\text { ". }\end{array}$ & $\begin{array}{l}: \\
\text { john@ } \\
\text { gmail. } \\
\text { com } \\
\text { No } \\
\text { Telp: } \\
08229 \\
84188 \\
\text { Usern } \\
\text { ame: } \\
\text { john } \\
\text { Passw } \\
\text { ord: } \\
\text { (Koso } \\
\text { ng) } \\
\text { Passw } \\
\text { ord } \\
\text { Lagi : } \\
\text { (Koso } \\
\text { ng) }\end{array}$ & & & \\
\hline 7 & $\begin{array}{l}\text { Mengi } \\
\text { si } \\
\text { semua } \\
\text { data } \\
\text { yang } \\
\text { ada di } \\
\text { pendaf } \\
\text { taran } \\
\text { pelang } \\
\text { gan } \\
\text { secara } \\
\text { lengka } \\
\text { p dan } \\
\text { benar }\end{array}$ & $\begin{array}{l}\begin{array}{l}\text { Nama } \\
\text { Pelang } \\
\text { gan } \\
\text { john }\end{array} \\
\text { Jenis } \\
\text { Kelam } \\
\text { in : } \\
\text { Laki- } \\
\text { Laki } \\
\text { Email } \\
: \\
\text { john@ } \\
\text { gmail. } \\
\text { com } \\
\text { No } \\
\text { Telp: } \\
\text { 08229 } \\
84188 \\
\text { Usern } \\
\text { ame: } \\
\text { john } \\
\text { Passw } \\
\text { ord: }\end{array}$ & $\begin{array}{l}\text { Sistem } \\
\text { menerima } \\
\text { akses } \\
\text { kemudian } \\
\text { silahkan } \\
\text { login } \\
\text { kembali } \\
\text { di menu } \\
\text { login } \\
\text { pelangga } \\
\text { n, dan } \\
\text { setelah } \\
\text { login } \\
\text { benar } \\
\text { maka } \\
\text { masuk } \\
\text { sebagai } \\
\text { member } \\
\text { dan dapat } \\
\text { berbelanj } \\
\text { a }\end{array}$ & $\begin{array}{l}\text { Sesuai } \\
\text { Harap } \\
\text { an }\end{array}$ & $\begin{array}{l}\text { Vali } \\
d\end{array}$ \\
\hline
\end{tabular}

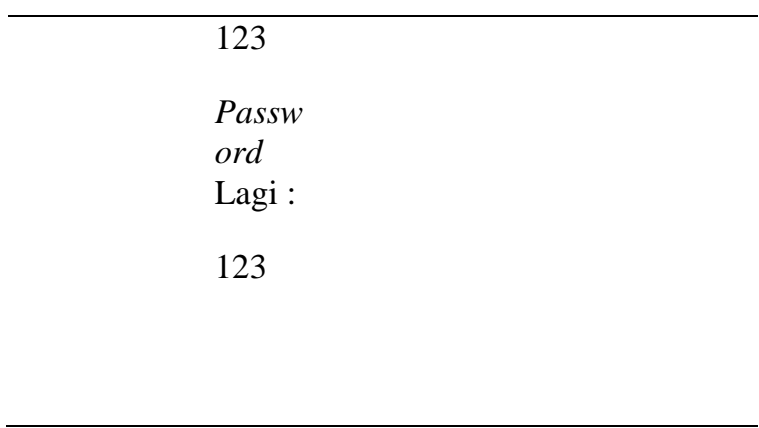

\section{KESIMPULAN}

Berdasarkan hasil analisa yang dilakukan pada bab sebelumnya, maka dapat diambil kesimpulan sebagai berikut :

1. Aplikasi ini diharapkan dapat membantu (pengguna) dalam melakukan proses transaksi pemesanan perlengkapan dan peralatan olah raga serta dapat meminimalkan anggaran pengeluaran biaya produksi.

2. Mempermudah dalam pengecekan jumlah barang perlengkapan peralatan olahraga.

3. Mempermudah perusahaan dalam menyebarluaskan informasi dan promosi produk

\section{REFERENSI}

Anhar. (2016). Panduan Bijak Belajar Internet untuk Anak. Sukabumi: Adamssein Media.

Ardhan, K. Y. (2012). PHP Menyelesaikan Website 30 Juta! Purwokerto: Jasakom.

Pratama, I. P. A. E. (2015). E-Commerce, E-Business dan Mobile Commerce. Bandung.

Sukamto, R. A. dan M. S. (2014). Rekayasa Perangkat Lunak. Bandung: Informatika Bandung. Bandung.

\section{PROFIL PENULIS}

Sinta Rukiastiandari. Tahun 2008 Lulus S1 Fakultas Teknologi Industri, Jurusan Teknik Informatika Universitas Gunadarma. Tahun 2011 Lulus S2 Magister Manajemen Sistem Informasi, Universitas Gunadarma

Yohanes Ulu Mado dengan NIM : 12140511, mahasiswa AMIK Bina Sarana Informatika Bekasi yang beralamat di Jl. Cut Mutiah No. 88, Bekasi 